\title{
Two Alternative Sequences of WTO Negotiations: Implications for Welfare
}

\author{
Basudeb Guha-Khasnobis \\ United Nations University - World Institute \\ for Development Economics Research
}

\begin{abstract}
We develop a partial equilibrium, sequential model of trade negotiation between an OECD country and two developing countries. First, we show that there are substantive qualitative and quantitative differences in the state of market access and domestic support that emerge under possible alternative sequences in which the negotiating game can be played. We then explore the welfare implications of such alternative sequences on the various stakeholders within the OECD. The welfare outcomes point to various lobbying activities which can influence the trade negotiator and contribute to the confusion and disagreement on who should commit to its policies first.
\end{abstract}

- JEL Classifications: C72, F12, F13

- Key words: WTO, Sequential, Welfare, Lobbying, Tariffs

\section{Introduction}

Although tariff barriers on the average have declined both under the GATT as well as the WTO, there is considerable skepticism in the developing countries about whether the rule-based, reciprocity driven organization (the WTO) is capable of fulfilling the special needs of the developing countries. The past decade

\footnotetext{
*Corresponding address: Basudeb Guha-Khasnobis UNU-WIDER, Katajanokanlaituri 6B; Helsinki; 00200, Finland. Phone: 3589-6159911, Fax: 3589-61599333, E-mail: basudeb@wider.unu.edu. (c)2004-Center for International Economics, Sejong Institution, All Rights Reserved.
} 
of multilateral trade negotiations ${ }^{1}$ has witnessed an increasing divide between the developed and the developing countries on a range of issues, including market access, domestic support, competition policy, labor standards and the movement of "natural persons". The seriousness of the differences is apparent from the complete failures of at least two proposed rounds of talks - Seattle and Cancun. These two, and several other proposed meetings to carry the multilateral process forward have often failed to get off the ground because neither the developed nor the developing countries have agreed to commit to a set of, supposedly freer, trade policies by acting as the leader.

The key principle on which the WTO functions is reciprocity, which implies that in order to receive trade-related preferences ${ }^{2}$, a country must be willing to offer similar benefits to the partner trading country. It is thus necessary for potential trade partners to meet to discuss, negotiate and commit to trade policies and preferences. There seems to be very limited information available to the outsider on exactly how negotiations (at least the successful ones) are conducted in the WTO "Green Room" (Bond, Ching and Lai, 2000), especially, if they are sequential or simultaneous processes.

The main tangible outcomes of such negotiations are applied tariff and subsidy rates. Some successful agreements notwithstanding, both the developing as well as the developed countries feel that commitments to improved market access made during the Uruguay Round have not been fulfilled one way or the other. Specifically, discriminatory tariff rates continue to affect exports directly, while domestic support (mainly in the form of subsidies) does so indirectly, in both sets of countries. Therefore, the developing countries as a group want the developed (OECD) countries to commit themselves to grater market access first, in terms of eliminating the residual protection, and vice versa! The entire process of new negotiations thus often falls flat as a non-starter.

In this paper we investigate a number of issues related to such failures or difficulties of new WTO negotiations to commence. We examine how the outcomes (with respect to tariff and subsidy rates as well as the standard welfare measures) differ, depending on who assumes leadership in a sequential game of negotiations. Next, we try to find a reason behind why a country, developed or developing, may be reluctant to be the Stackelberg-leader, even if it had the necessary information

\footnotetext{
${ }^{1}$ See Bhagwati (1993) for a discussion of multilateralism.

${ }^{2}$ For a detailed analysis of reciprocity, see Bagwell and Staiger (1994).
} 
about its rival's strategies. In particular, we explore the role of differential lobbying power or political influence of the various domestic stakeholders in any country in explaining the reluctance of its trade negotiator to act as the leader, even if it may otherwise be optimal to do so.

One can hardly do justice trying to cover the vast, rich literature on strategic trade policy on the whole ${ }^{3}$. On subsidies and countervailing tariffs in particular, Collie (1991) shows that in the context of a Cournot oligopoly model, with incumbent foreign firms facing the potential entry of domestic firms, the optimal foreign policy is to subsidize exports. When the domestic country can retaliate with a countervailing tariff, the optimal foreign export subsidy is zero. When the domestic country retaliates with a tariff as well as a production subsidy, the optimal foreign export subsidy may be positive. However, for ease of exposition, and also because the main focus is on the implications of alternative sequential game scenarios, both production and consumption of the single good do not take place in the same country in our model. Thus, a country using both a tariff as well as a production subsidy is beyond the scope of the present model. Collie (1994) models trade policy as a multi-stage game to examine the effect of retaliation, with the help of countervailing tariffs, on the profitshifting argument of subsidies. Another strand of the strategic trade policy literature which is indirectly related to our model is that on tariff preferences and trade blocs. Adriamananjara (2000) uses a Cournot oligopoly model with a single homogeneous good to model tariff preferences. In this model countries outside the trading blocs move sequentially. He considers the incentives to both the outside country and the inside countries of allowing one outside country to join a bloc. Collie (1997) considers the effect of exogenous trade bloc enlargement in a multi-country version of the Brander-Spencer export subsidy game. It is shown that trade bloc enlargement leads to a reduction in the Nash equilibrium export subsidies, thereby increasing the welfare of the exporting countries. Although the welfare of the importing countries decreases, world welfare may increase if the export subsidies are financed by distortionary taxation.

\section{The Model}

We consider a model of trade negotiations between one developed (importing, OECD) and two developing (exporting, DC) countries. In our partial equilibrium

\footnotetext{
${ }^{3}$ One of the most widely quoted references being Brander and Spencer (1985).
} 
model there are two firms, one in each DC, selling an identical product $(\mathrm{Q})$ in the OECD country. For simplicity, we assume that the firms do not sell the product in their home markets, and, no firm in the OECD country produces an identical product. ${ }^{4}$ In order to maximize respective national welfares, the OECD government chooses tariffs on the imports from each developing country separately ${ }^{5}$ whereas the DC governments choose subsidy rates for their respective domestic firms in order to maximize exports, net of subsidy. Given the tariff and subsidy rates announced by the respective governments, the DC firms choose output levels to maximize their respective profits.

The following notations are used.

$P$ : price of the good in the OECD country.

$q(1), q(2)$ : output levels of the two DC firms.

$t(1), t(2)$ : tariffs imposed by the OECD on the two DC's, respectively.

$s(1), s(2)$ : subsidies provided to the two firms by their respective (DC) governments.

$c(1), c(2)$ : unit costs incurred by the two firms, respectively.

Let $P=1-Q$, where $Q=q(1)+q(2)$, represent the inverse demand function for the product.

DC governments 1 and 2 maximize their export earnings, net of subsidy ${ }^{6}$. These are, respectively,

(1) $X(1)=[P-t(1))-s(1)] q(1)$

and

(2) $X(2)=[P-t(2))-s(2)] q(2)$

The DC firms maximize profits. These are, respectively,

(3) $\Pi(1)=[P-t(1))+s(1)] q(1)-c(1) q(1)$

and

(4) $\Pi(2)=[P-t(2))+s(2)] q(2)-c(2) q(2)$

The OECD government maximizes

${ }^{4}$ Instead, the OECD firm(s) produces a product which is a close substitute. The implications for the $\mathrm{OECD}$ welfare function are described later.

${ }^{5}$ See Sheih. S and M. Shi (1996) for a comparison between Most Favoured Nation (MFN) and Preferential Tariff Regime (PTR) as optimal choices of tariff regimes.

${ }^{6}$ Foreign exchange constrained LDCs are the best examples where such objective functions are extremely relevant. 
(5) $L=1 / 2[q(1)+q(2)]^{2}+t(1) q(1)+t(2) q(2)-[s(1)+s(2)]^{2}$

The welfare function of the OECD government comprises three conceptually different parts, consumer's surplus, tariff revenues and producers loss. The first part, $1 / 2[q(1)+q(2)]^{2}$ represents consumer's surplus ${ }^{7}$. The second component $t(1) q(1)+t(2) q(2)$ is the tariff revenue. The quadratic component $[s(1)+s(2)]^{2}$ representing producer's loss can arise from a wide range of specific demand and cost functions if the product of OECD firm(s) (not explicitly modeled) is a close but imperfect substitute of Q. We examine two alternative scenarios with respect to the sequence in which the game is played.

Scenario One: The OECD country acts as the Stackelberg-leader and sets its tariffs optimally (by choosing its most preferred points on the DC governments' reaction curves, and, the DC firms reaction curves). Next, the DC firms take these tariff rates as given and choose their subsidy rates simultaneously (by picking the most preferred points on the DC firms' reaction curves). Finally, the DC firms choose their optimal outputs simultaneously, given both tariffs and subsidy rates.

Scenario Two: The DC governments act as the Stackelberg-leaders and set their respective subsidy rates optimally (by choosing their most preferred point on the OECD reaction curve, and the DC firms' reaction curves). Next, the OECD takes these subsidies as given and chooses its tariff rates (by picking its most preferred points on the DC firms', not governments', reaction curves). Finally, DC firms, as before, choose their optimal quantities, given tariffs as well as subsidy rates. In both the cases, the sub-game perfect equilibrium of the three stage game comprises the set of optimal tariffs, subsidies, and outputs.

The entire game is a combination of sequential and simultaneous moves. The OECD, the two DC governments taken together, and the two DC firms taken together, act sequentially. However, between themselves, the two DC governments as well as the two DC firms act simultaneously. The term Stackelbergleader (or follower), naturally, refers to the sequential part of the game.

\section{A. Scenario One: The OECD government as the Stackelberg-leader}

The three-stage game is solved by backward induction. In Stage 3, the firms

\footnotetext{
${ }^{7}$ The consumer's surplus component is the difference between the definite integral of the inverse demand function from 0 to $Q$, and $P Q$. It is easy to verify that the consumer's surplus is $1 / 2[q(1)+q(2)]^{2}$.
} 
take tariffs and subsidies as given and choose their respective output levels. Solving their respective first order conditions of profit maximization yields the output levels as functions of $\mathrm{t}, \mathrm{s}$ and $\mathrm{c}$. Specifically,

(6) $q(1)=1 / 3+1 / 3[t(2)-2 t(1)]-1 / 3[s(2)-2 s(1)]+1 / 3[c(2)-2 c(1)]$

(7) $q(2)=1 / 3+1 / 3[t(1)-2 t(2)]-1 / 3[s(1)-2 s(2)]+1 / 3[c(1)-2 c(2)]$

The total output produced by the two firms together is

(8) $Q=q(1)+q(2)=2 / 3-1 / 3[(t(1)+t(2))-(s(1)+s(2))+(c(1)+c(2))]$

In Stage 2, the two DC Governments take the OECD tariffs as given and choose their respective subsidy levels simultaneously to maximize their respective net exports. The first order conditions of net export maximization are obtained by differentiating $X(1)$ and $X(2)$, with respect to $s(1)$ and $s(2)$, respectively. Since the DC governments pick their most preferred points on the DC firms' reaction curves $^{8}$, in the first order conditions, we replace $q(1)$ and $q(2)$ with their optimal levels from the firms' profit maximization outcomes obtained in Stage 3, and arrive at:

(9) $4 t(1)-2 t(2)+2 s(2)-16 s(1)+10 c(1)-2 c(2)=2$

(10) $4 t(2)-2 t(1)+2 s(1)-16 s(2)+10 c(2)-2 c(1)=2$

Solving them simultaneously, we obtain the optimum levels of $s(1)$ and $s(2)$ as functions of $\mathrm{t}(1), \mathrm{t}(2), \mathrm{c}(1)$ and $\mathrm{c}(2)$ as follows.

(11) $s(1)=1 / 21[5 t(1)-2 t(2)+13 c(1)-c(2)-3]$

(12) $s(2)=1 / 21[5 t(2)-2 t(1)+13 c(2)-c(1)-3]$

In Stage1, the OECD government chooses tariff levels to maximize net welfare defined in Equation 5. As the Stackelberg-leader, the OECD country chooses its most preferred points on both the DC governments' as well as the DC firms' reaction functions. Therefore, after substituting the optimum levels of $q(1), q(2)$, $s(1)$ and $s(2)$ in terms of $t(1), t(2), c(1)$ and $c(2)$ obtained from the DC governments' and firms' optimizations in Stages 3 and 2, the first order conditions of the OECD may be solved to obtain the optimum levels of $t(1)$ and $t(2)$ in terms of the exogenous parameters $c(1)$ and $c(2)$ as follows:

(13) $t(1)=.34-.46 c(1)-.26 c(2)$

(14) $t(2)=.34-.46 c(2)-.26 c(1)$

Substituting $\mathrm{t}(1)$ and $\mathrm{t}(2)$ back in the expressions for optimum $s(1)$ and $s(2)$, we get

(15) $s(1)=.53 c(1)-.06 c(2)-.09$

\footnotetext{
${ }^{8}$ Thus, the DC governments are the Stackelberg-followers with respect to the OECD, but the Stackelbergleaders with respect to the DC firms.
} 
(16) $s(2)=.53 c(2)-.06 c(1)-.09$

Note that national subsidy levels vary directly with the costs faced by domestic producers and inversely with the costs faced by the competing foreign (the other DC) producers. Next, by substituting back $t(1), t(2), s(1)$ and $s(2)$ in the expressions for optimum $q(1)$ and $q(2)$, we get

(17) $q(1)=.19+.14 c(2)-.07 c(1)$

(18) $q(2)=.19+.14 c(1)-.07 c(2)$

Quantity supplied by a firm is inversely proportional to its own cost and directly proportional to the cost faced by the competitor in the other country. Total supply in the market is the sum of $q(1)$ and $q(2), Q=.38+.07[c(1)+c(2)]$, which is positive for any values of $c(1)$ and $c(2)$.

The corresponding market price, implied by the inverse demand function, is

(19) $P=1-Q=.62-.07[c(1)+c(2)]$

\section{B. Scenario Two: Developing countries as the Stackelberg-leaders}

In this alternative scenario (Scenario 2), the Developing Countries act as the Stackelberg-leaders. Once again, we solve the three stage game by backward induction. In Stage 3, as before, firms maximize profits, given tariff and subsidy rates. The analytical solutions are unchanged and not repeated here. In Stage 2, the OECD country takes the subsidy levels chosen by the two developing country governments as given and chooses its tariff levels to maximize its own welfare. Note that the key difference in the maximization exercise is that $s(1)$ and $s(2)$ are now exogenously given to the OECD government and not functions of its tariff levels as in the first scenario. However, the OECD still picks its most preferred points on the DC firms' reaction curves ${ }^{9}$. We solve the first-order-conditions to obtain optimum $t(1)$ and $t(2)$ as functions of $c(1)$ and $c(2)$, and $s(1), s(2)$. To differentiate them from the optimum $t(1)$ and $t(2)$ obtained earlier (where the OECD was the Stackelberg-leader), we use asterisks as superscripts. Thus,

(20) $t(1) *=1 / 4+3 / 8 s(1)-1 / 8 s(2)+1 / 8 c(2)-3 / 8 c(1)$

\footnotetext{
${ }^{9}$ Thus, the OECD is the Stackelberg-follower with respect to the DC governments, but The Stackelberg-
} leaders with respect to the DC firms. 
(21) $t(2) *=1 / 4+3 / 8 s(2)-1 / 8 s(1)+1 / 8 c(1)-3 / 8 c(2)$

In Stage 1, the DC governments maximize their own welfare functions as the Stackelberg-leaders with respect to both the OECD government as well as the DC firms. Solving simultaneously the two first order conditions yield:

(22) $s(1)^{*}=.61 c(1)-.02 c(2)-.16$

(23) $s(2)^{*}=.61 c(2)-.02 c(1)-.16$

Working backwards, we can now solve for optimal tariff levels as

(24) $t(1)^{*}=.21+.05 c(2)-.15 c(1)$

(25) $t(2)^{*}=.21+.05 c(1)-.15 c(2)$

There is a significant change in the solution for optimal tariffs, compared to the earlier case. When the OECD government acts as the Stackelberg-leader, its tariff levels varied inversely with the cost levels of both the developing countries. In the present case, when developing countries act as the Stackelberg-leaders, the ensuing tariff rates that the OECD country chooses continues to vary inversely (with a much smaller coefficient) with the partner developing country's cost level as before, but directly with that of its rival (the other developing country). On both counts, the tariff levels in this scenario are likely to be higher, partially offsetting the leader "advantage" the developing countries may have earned by committing to subsidy levels first. Thus, the DC governments choose higher subsidies when they act as leaders, aiming to wrest market share from its rival. The OECD government offsets this initiative somewhat, by choosing its tariff against a particular DC that is directly proportional to the cost level of the rival DC. Also, the coefficient of inverse variation of the tariff rates with respect to the respective DC's own cost levels, are much smaller. The exact quantitative differences in the various rates between the two regimes depend on the values of the parameters of the model $[c(1)$ and $c(2)]$.

The optimum quantity levels in Scenario 2 are given as

(26) $q(1)^{*}=.29+.04 c(2)-.15 c(1)$

(27) $q(2)^{*}=.29+.04 c(1)-.15 c(2)$

Total output in the market is given by the sum of $\mathrm{q}(1)$ and $\mathrm{q}(2)$ as

(28) $Q^{*}=q(1)^{*}+q(2)^{*}=.58-.11[c(1)+c(2)]$ and

(29) $P=.42+.11[c(1)+c(2)]$.

The two sets of results are presented in the text boxes below. 


\begin{tabular}{|l|}
\hline Scenario 1:OECD goes first \\
$t(1)=.34-.46 c(1)-.26 c(2)$ \\
$t(2)=.34-.46 c(2)-.26 c(1)$ \\
$s(1)=.53 c(1)-.06 c(2)-.09$ \\
$s(2)=.53 c(2)-.06 c(1)-.09$ \\
$q(1)=.19+.14 c(2)-.07 c(1)$ \\
$q(2)=.19+.14 c(1)-.07 c(2)$ \\
$Q=.38+.07[c(1)+c(2)]$, \\
$P=1-Q=.62-.07[c(1)+c(2)]$
\end{tabular}

Scenario 2 : DC's go first
$t(1)^{*}=.21+.05 c(2)-.15 c(1)$
$t(2)^{*}=.21+.05 c(1)-.15 c(2)$
$s(1)^{*}=.61 c(1)-.02 c(2)-.16$
$s(2)^{*}=.61 c(2)-.02 c(1)-.16$
$q(1)^{*}=.29+04 c(2)-.15 c(1)$
$q(2) *=.29+.04 c(1)-.15 c(2)$
$Q^{*}=58-.11[c(1)+c(2)]$

We note that in Scenario 2, for sufficiently high levels of $c(1)$ and $c(2)$, the market for this commodity may not exist at all. The logic is as follows. Given the opportunity to act as the Stackelberg-leader and commit to subsidy rates optimally, developing countries choose these rates varying directly, and more strongly (compared to the case where the OECD acts as the leader and commits to its optimal tariffs) with their respective firms' cost levels. The OECD reacts by trying to reduce this first-mover advantage by imposing a tariff on a DC that varies directly with the rival DC suppliers cost level. When this cost level is sufficiently high, the tariff level may also be prohibitively high. Since there are no domestic markets in this model, such high tariffs wipe out not just trade, but in effect, the entire existence of this market. In the subsequent analysis, we restrict our attention to the range of $c(1)$ and $c(2)$ values for which both the firms choose positive outputs in both the scenarios.

To understand the main qualitative implications of scenario1 relative to scenario 2, we use a series of graphs depicting the different solutions as well as their differences between scenarios. In all of the graphs to follow, $c(1)$ is measured along the horizontal $(x)$ axis, whereas $c(2)$ is measured along the vertical $(y)$ axis. Accordingly, in the functions representing the different graphs, the variables $x$ and y stand for $c(1)$ and $c(2)$, respectively. 
Figure 1. feasible set of cost levels

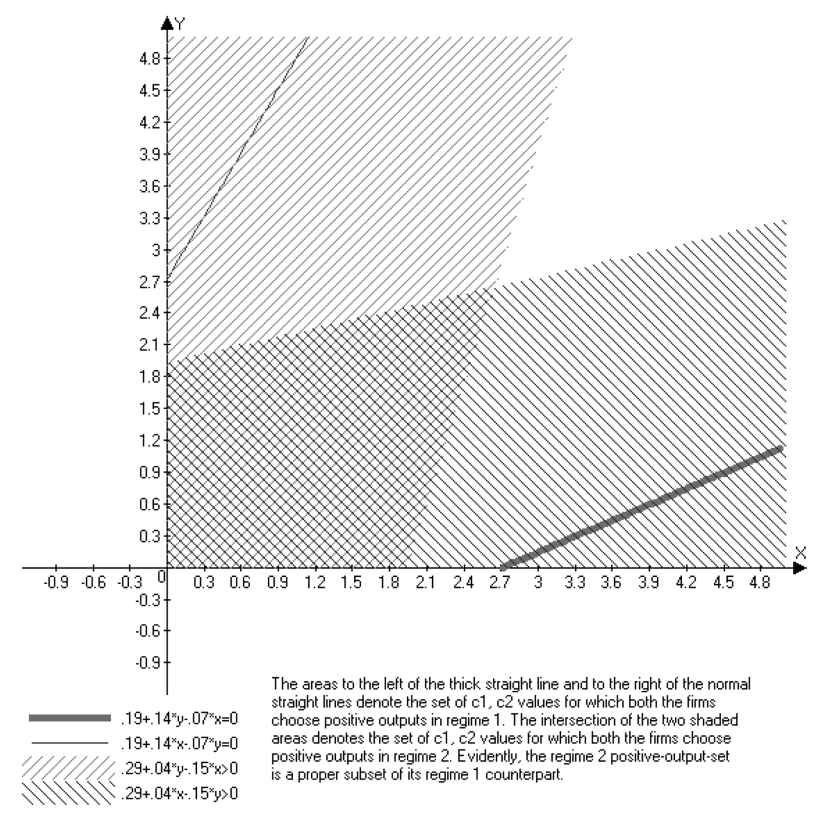

It is clear from the graph that as long as $c(1)$ and $c(2)$ are each less than or equal to (approximately) 2, total output under the second scenario is positive. Henceforth, we shall narrow the domain of $(c(1), c(2))$ to the interval $(2,2)$.

We now compare the tariff and subsidy levels under the two sequential scenarios. In each of the graphs to follow, we have plotted the set of $c(1), c(2)$ for which outputs of both the firms are positive in scenario 2 , and the relevant comparative variable (i.e., tariff or subsidy differentials). In calculating "differences", we subtract the scenario 1 outcomes from their counterparts in scenario 2 .

In Figure 2, the intersection of the three sets depict the set of $c(1), c(2)$ values, within the closed set $(2,2)$, for which tariff rates chosen by the OECD government are higher if the DC governments act as the Stackelberg-leaders. The size of this set relative to $(2,2)$ can be interpreted as follows. Usually, exact knowledge about firms' cost levels is not available to outsiders, including the WTO. However, in the present case, the odds (or probability) favor costs lying in the range which will result in higher tariffs in scenario 2. Therefore, the institution (such as the WTO) which may be involved in setting the rules or modalities of negotiations, will be aware that if the DC governments are to commit to subsidy levels first, prevailing cost levels are more likely to result in subsequent tariff rate choices by the OECD which are higher than what would have chosen if it were to act as the Stackelberg- 
Figure 2. tariff rate comparison

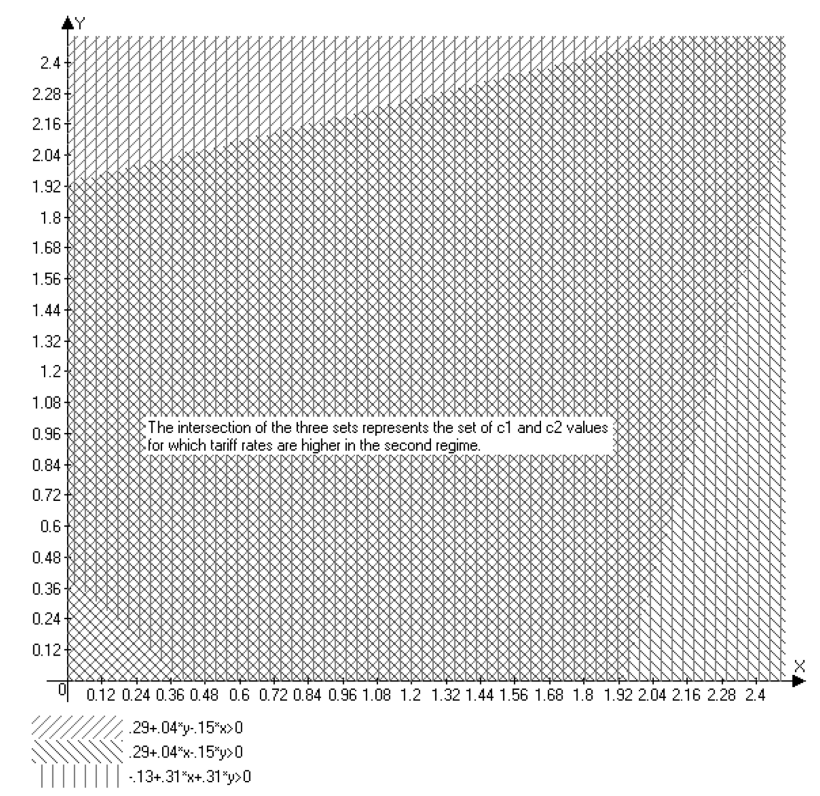

Figure 3. subsidy rates comparison

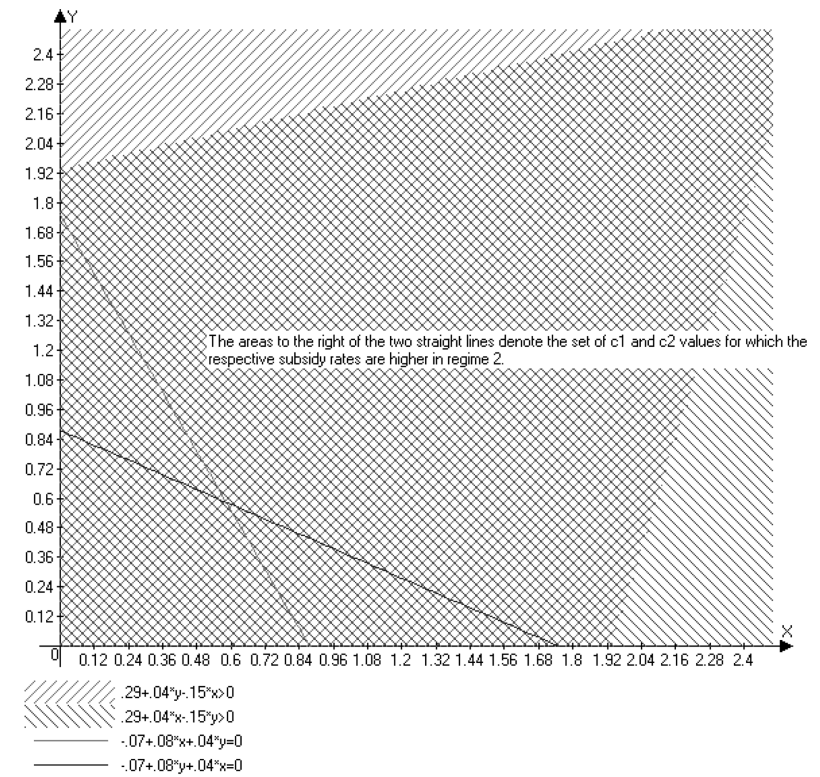

leader instead. In other words, market access will be restricted if the negotiations follow this particular sequence.

The implications are similar for subsidy rates too (Figure 3). Thus, trade 
distorting taxes are generally more likely to be higher if the developing country governments act as Stackelberg-leaders in this model.

\section{Welfare effects: Implications for lobbying}

In this section, we compare the welfare effects of the two negotiating sequence scenarios. As in the previous section, we subtract the value of the relevant variable under the scenario where the OECD is the Stackelberg-leader from that under the scenario 2 where the developing countries are the Stackelberg-leaders. OECD welfare has three components. The first is "consumer's surplus (CS)", the difference between the two scenarios in which, in the present model is given by

$$
\Delta C S=1 / 2 Q^{* 2}-1 / 2 Q(2)=.09-.08 c(1)-.08 c(2) \text {. }
$$

From Figure 4, it is clear that the likelihood (implied by potential cost structures) of consumers in the OECD being better off is very small if the DC governments act as leaders. The second component in OECD welfare is "tariff revenue (TR)". The change in tariff revenue between the two scenarios of negotiation is given by

Figure 4. consumers surplus in OECD

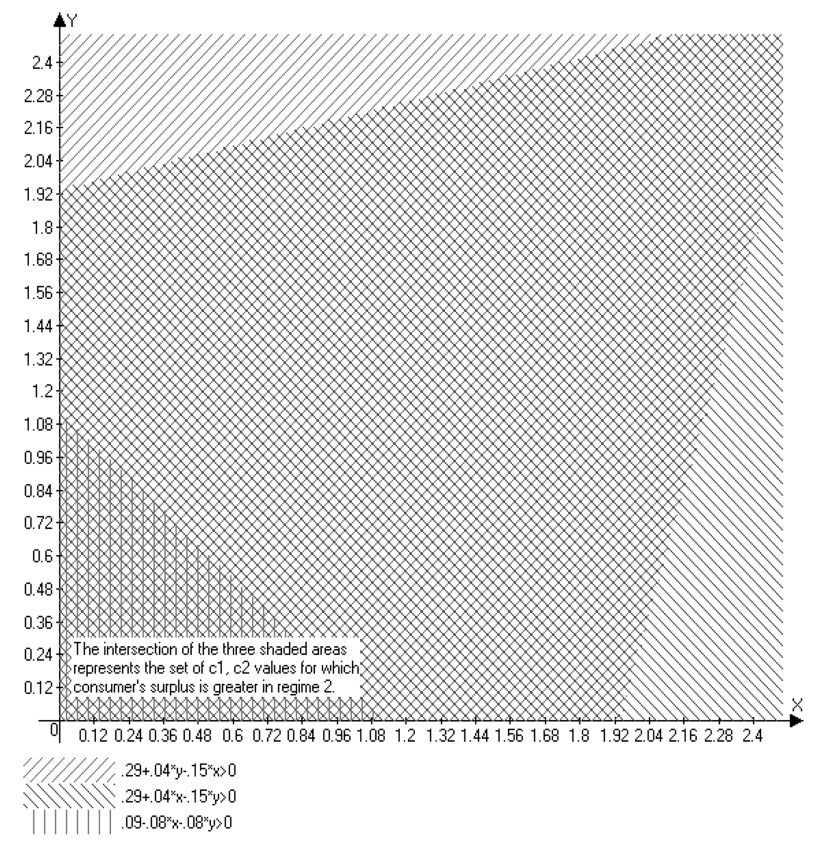




$$
\begin{aligned}
& \Delta T R=\left(t(1)^{*} q(1)^{*}+t(2)^{*} q(2)^{*}\right)-(t(1) q(1)+t(2) q(2)) \\
& =.04 c(1)+.04 c(2)+.02 c(1)^{2}+.02 c(2)^{2}+.10 c(1) c(2)
\end{aligned}
$$

This is unambiguously positive, implying that OECD tariff revenues are higher in Scenario 2. The third and final component of OECD welfare is "producers loss (PL)", the change in which is given by

$$
\begin{aligned}
& \Delta P L=\left(s(1)^{*}+s(2)^{*}\right)^{2}-(s(1)+s(2))^{2} \\
& =.07-.20 c(1)-.20 c(2)+.24 c(1) c(2)+.12 c(1)^{2}+.12 c(2)^{2}
\end{aligned}
$$

It is evident from Figure 5 that cost levels are more likely to be such that OECD producers are worse off if developing countries act as Stackelberg-leaders during negotiations. This is expected, since we have already seen that subsidy rates are likely to be higher in Scenario 2, leading to a higher quadratic loss function for OECD producers.

If the negotiating countries will agree to a particular "sequence" of proposed actions or not will depend critically on the comparative fates of the different stakeholders in their respective home countries. Neither the consumers, nor the producers in the OECD would want the DC governments to act as Stackelberg leaders. It is only the revenue department in the OECD government that stands to gain if the DCs act as Stackelberg-leaders.

Figure 5. OECD producers loss comparison

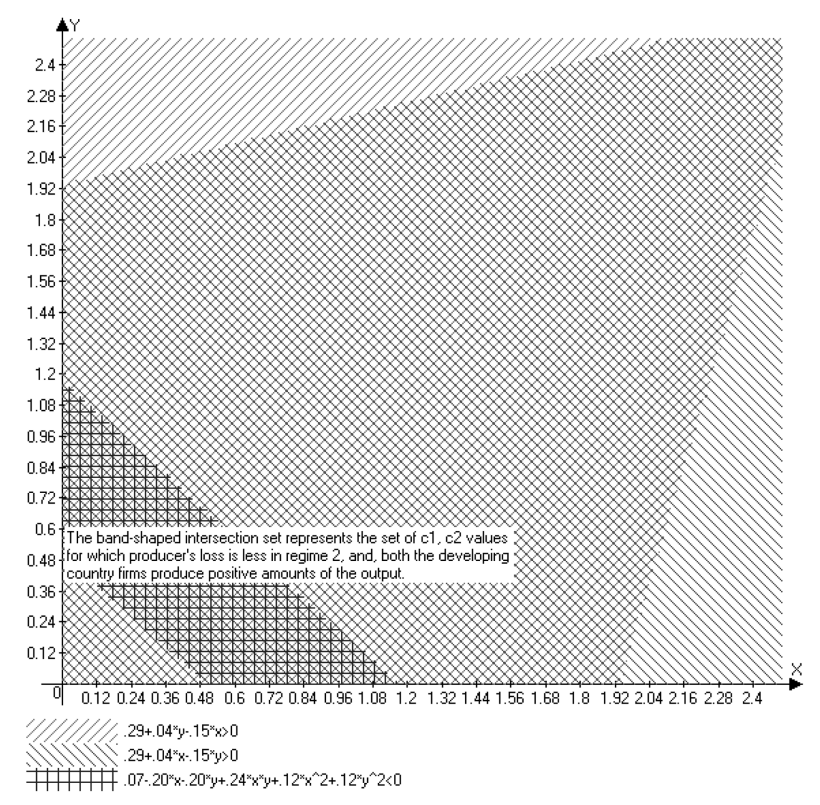


Figure 6 summarizes the political feasibility, on paper, in the OECD of a negotiating sequence in which the developing countries act as leaders.

Evidently, the small range of $c(1), c(2)$ values for which all the stakeholders gain suggests that if the OECD government were to make all the three different stakeholder groups better off after the negotiations (and was equally persuaded by the three groups), it should prefer to act as the Stackelberg-leader. The question is: which group of stakeholders exerts the maximum influence on the OECD trade negotiator? In other words, does differential lobbying power of the three stakeholder groups explain why the OECD negotiator may be reluctant to act as the Stackelberg-leader even when it seems the optimal thing to do?

At least on paper, there may be scope for redistribution amongst stakeholders, to make everyone better off. To see this, consider the net welfare change for the OECD, which is the sum of these three stakeholders welfare components (their changes) and is given by

$$
\Delta W=(C S+T R-P S)^{*}-(C S+T R-P S)=.02+.16^{*} c(1)+.16^{*} c(2)-.10 c(1)^{2}-.10 c(2)^{2}-.14 c(1)
$$
$c(2)$

Figure 6. Political feasibility of Scenario 2 in the $\mathrm{OECD}^{10}$

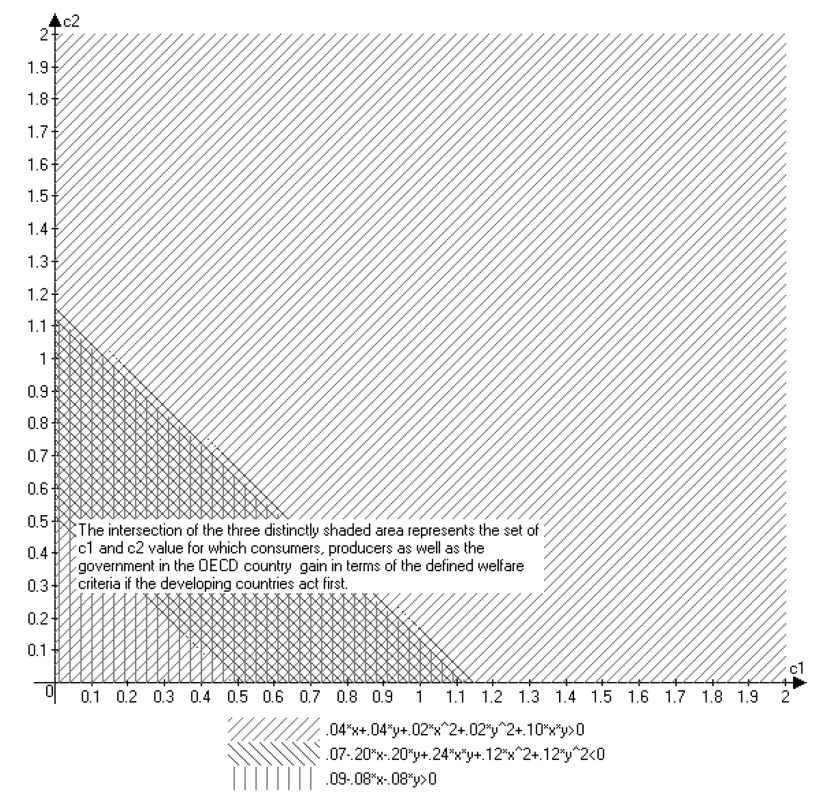

\footnotetext{
${ }^{10}$ In this and subsequent figures the expression "goes/acts first" means the Stackelberg-leader.
} 
Figure 7. Net change in OECD welfare and the scope for redistribution

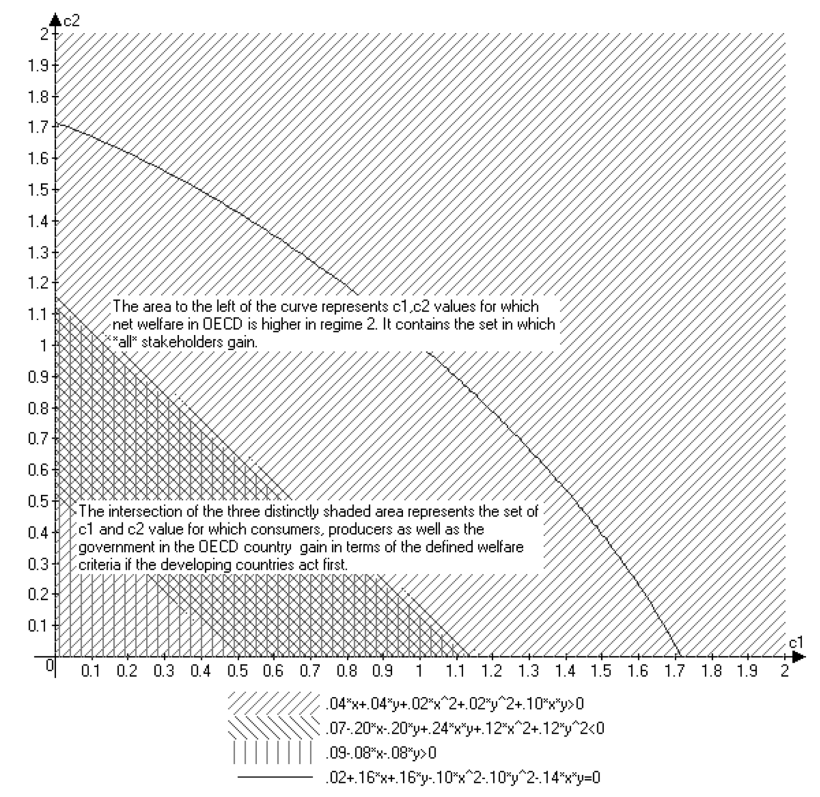

If costs lie to the left of the curve, net welfare in the OECD country is higher if developing countries act as leaders and choose optimal subsidies. As we have seen earlier, the chief source of positive welfare gain is from enhanced tariff revenues, which, supposedly, accrues to the government. If costs lie to the left of the curve, but outside the intersection-band which implies gains for all stakeholders, the government can potentially redistribute the tariff revenues to compensate the losers. If the costs lie to the right of the curve, there cannot be any scope for redistribution which can make everyone better off in Scenario 2.

The area to the left of the curve is the "low-cost" zone in our overall set of feasible cost levels. One may argue that cost levels are lower in the more advanced developing countries with better technologies. Therefore, from the OECD's point of view, with redistribution it is optimal and politically feasible (in the absence of differential lobbying pressures from the three stakeholder groups) to see a negotiating sequence where a relatively advanced developing country acts as a Stackelberg-leader. The same logic suggests that with technologically backward, hence high-cost, countries, the OECD country must commit to tariff levels first, by acting as the leader. The failures of trade talks to commence due to quarrels regarding who should commit first are a result of lobbying pressures from small but influential groups. Such failures do not have a strict economic rationale in this 
model.

"Welfare" in the two developing countries is synonymous with net exports in this model, which are, respectively, .03-.11c(1)-.06c(2)+.05c(1 $)^{2}-.03 c(2)^{2}$ and .03-.11c (2) $-.06 c(1)+.05 c(2)^{2}-.03 * c(1)^{2}$. As Figure 8 demonstrates, DCs gain in Scenario 2 (that is, when they act as leaders) under quite extreme cost structures. To be precise, in scenario 2 ,

(a) both of the DCs gain if their costs levels are both very low, and

(b) if the cost-asymmetry between the developing countries is extreme, the high-cost developing country gains and the other loses.

\section{Conclusion}

The primary motivation behind the paper is to envisage $a$ logical framework to understand the political compulsions behind why some trade negotiations are delayed or aborted because parties differ on who should commit first to its trade policies (tariffs or subsidies to be precise). We find that under circumstances such

Figure 8. conflict of interest

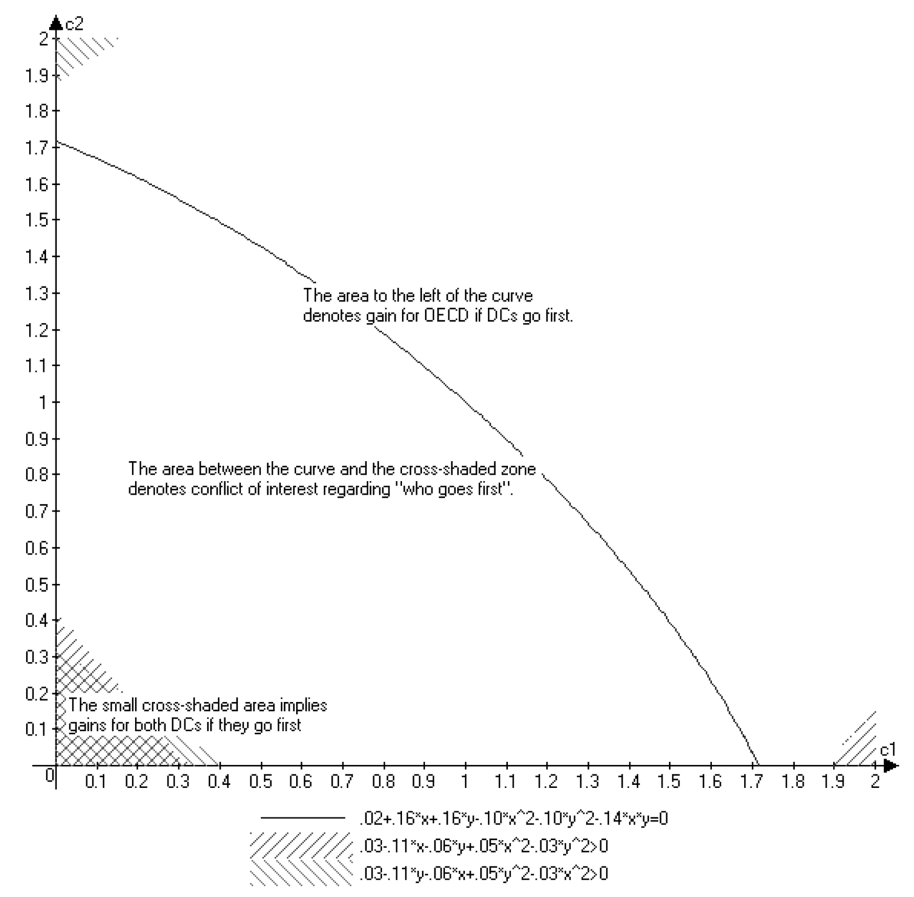


as the one described in the model, there are substantive welfare implications depending on which party sets tariff rates (or subsidies) first in a strategic sequential optimization exercise. The resulting states of market access as well as domestic support policies are considerably different in both qualitative and quantitative terms. The welfare implications of such alternative sequences on the various stakeholders within the OECD point to various lobbying activities which can influence the trade negotiator and contribute to the confusion and disagreement on who should commit to its policies first.

\section{Acknowledgements}

I wish to thank an anonymous referee of this journal for some invaluable constructive comments on an earlier draft.

Received 7 August 2003, Accepted 29 January 2004

\section{References}

Adrianamanjara, S. (2000), "On the Size and Number of Regional Integration Arrangements: A Political Economy Model”, Department of Economics, University of Maryland at College Park.

Bagwell, Kyle and Robert W Staiger (1994), "An economic theory of the GATT" nber Working Paper No 6049.

Bhagwati, J., "Regionalism and Multilateralism: An Overview," in De Melo and Panagariya (eds.), 1993.

Bond, Rick, Stephen Ching, Edwin Lai (2000), “Accession Negotiations in the WTO”, mimeo, City University of Hong Kong.

Brander, J. (1981) "Intra-Industry Trade in Identical Commodities." Journal of International Economics, 1: 1-14.

Brander, J. and P. Krugman. (1983) "A Reciprocal Dumping Model of International Trade." Journal of International Economics, 15: 313-321.

Brander, J.A. and B. Spencer (1985), "Export Subsidy and International Market Share Rivalry", Journal of International Economics, 15, 313.321.

Collie, David R, 1997. "Bilateralism Is Good: Trade Blocs and Strategic Export Subsidies," Oxford Economic Papers, Vol. 49 (4) pp. 504-20.

Collie, David, 1992. "Export Subsidies, Entry Deterrence and Countervailing Tariffs," The Manchester School of Economic \& Social Studies, Vol. 60 (2) pp. 136-51.

Collie, David (1994), 'Strategic Trade Policy and Retaliation', Japan and the World Economy, vol. 6, pp 75-88. 
Collie, David (1991), 'Export Subsidies and Countervailing Tariffs', Journal of International Economics, Vol. 31, pp. 309-324.

Shieh. S. and M. Shi (1996) "Initial Tariff Regimes, Cost Asymmetry, and Free- Trade Agreements: Is the low-cost country superior to the high-cost country as an FTA partner?" mimeo, Institute of Economics, Academia Sinica, Taipei.

\section{Appendix}

The net changes in Firms 1 and 2s profits (Scenario 2-Scenario 1) are, respectively, $-.02-.01 \mathrm{c}(1)-.03 \mathrm{c}(2)+.01 \mathrm{c}(1)^{2}+.01 \mathrm{c}(1) \mathrm{c}(2)$ and $-.02-.01 \mathrm{c}(2)-.03 \mathrm{c}(1)+.01 \mathrm{c}(2)^{2}+.01 \mathrm{c}(1) \mathrm{c}(2)$

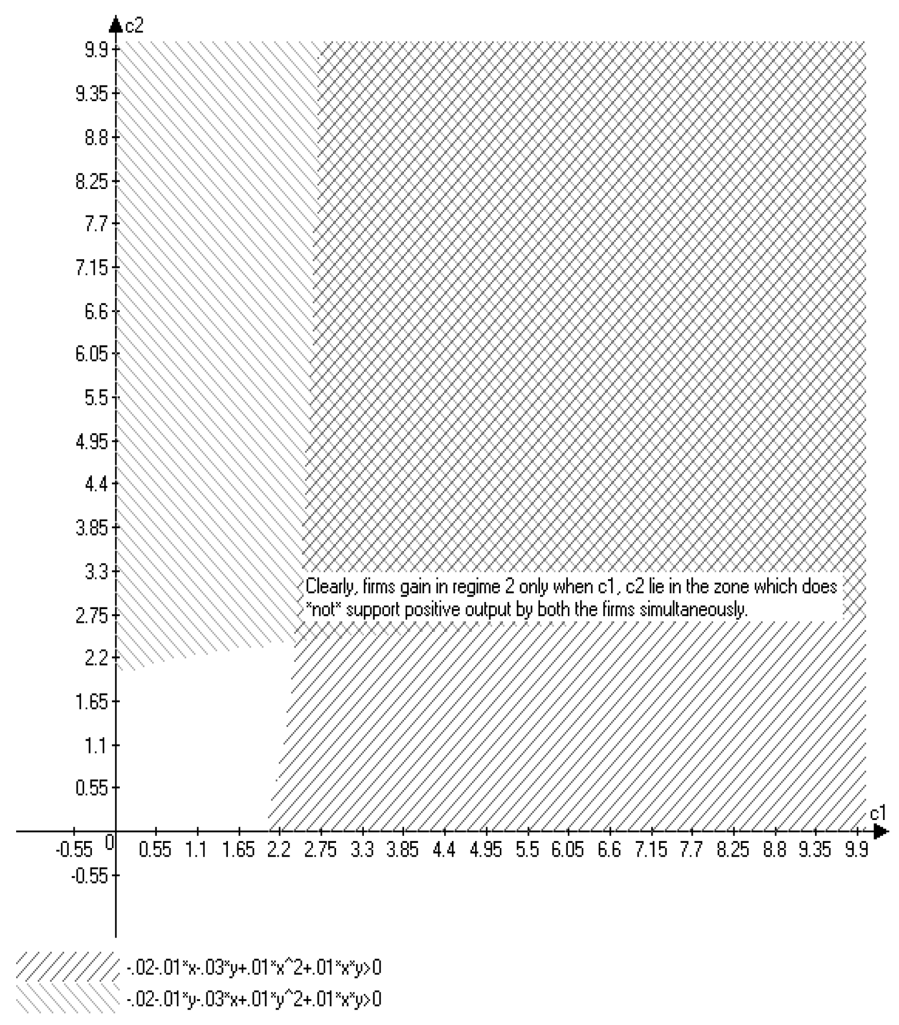

